\title{
苦乐七十年
}

李永舫

中国科学院化学研究所, 北京 100190

苏州大学材料与化学化工学部, 江苏苏州 215123

\section{Bittersweet Memories in the Past Seventy Years}

\section{Yongfang}

Institute of Chemistry, Chinese Academy of Sciences, Beijing 100190, P. R. China.

College of Chemistry, Chemical Engineering and Materials Science, Soochow University, Suzhou 215123,

Jiangsu Province, P. R. China.

Email: liyf@iccas.ac.cn

一天又一天, 一年又一年, 时间的进程不可逆 转, 不知不觉走到了人生的第七十个年头。常言道 “人生如一场梦”, 七十岁应该接近了这场 “梦” 的 尾声; 又言道 “人生如一杯酒”, 七十岁也快喝到 了这杯 “酒” 的杯底。《物理化学学报》为我七十 岁人生节点出版专辑, 我感到非常荣幸、但也感到 担当不起, 因为我只是一位普普通通的科研工作 者。但是无论如何, 非常感谢《物理化学学报》主 编刘忠范院士和编辑部各位老师对此专辑的热情 支持、以及我的学生们的精心筹划和准备。

我走过的这七十年, 经历了不少艰难困苦的 岁月, 有幼年的飘泊和动荡、三年困难时期的挨饿 和艰辛、文革的动乱和失去读大学机会的痛苦、农 村重体力劳动的劳累、家庭责任的重担、也有研究 工作中的挫折和申请科研经费的艰难。回首往事, 不禁感到心酸。不过, 人生苦乐相伴, 有苦也有甜。 我也有在乡下和小伙伴一起玩要的愉快、上学时 获得新知识的好奇和高兴、挨饿时吃顿饱饭的满 足、酷暑烈日下劳动后树荫下的凉爽、恢复高考后 重获读大学机会的兴奋、研究工作取得进展和申 请科研项目获得批准的喜悦、以及科研获奖登台 领奖的光荣。

我的同龄人相聚的时候, 常常抱怨生不逢时 和命苦。是的, 我们这一代人出生在解放前夕的战 争烽火中, 10 到 15 岁正长身体时遇到 1960 年前 后的自然灾害挨过饿, 1966 年高中毕业 18 岁正求
知识时遇到文化大革命失了学, 20 岁到 29 岁的人 生黄金年龄回乡当农民, 成家立业历尽艰辛。搞科 研也未能赶上国家重视青年科研人才的政策 (1994 年设立国家杰出青年基金时刚过 45 岁)。在 这坎坷的一代人中间, 我算是幸运的。我的父母在 家庭生活极端艰难困苦的情况下支持我读书、使 我能够坚持读到高中毕业; 1977 年我抓住了恢复 高考的机会、以 29 岁的 “高龄” 进入大学学习, 1979 年又抓住了提前报考研究生的机遇; 我的妻 子特别能吃苦, 在我读大学和研究生期间她带两 个孩子在农村种田担负起家庭的重担, 使我能够 全身心投入学习和科研。后来的读书和研究工作 比较顺利, 有幸受到过多位名师的指导和帮助, 包 括华东理工大学的胡英教授(物理化学(化学热力 学)专家、中国科学院院士, 硕士生阶段给我们讲 授“流体的分子热力学”课, 并且我为他讲授的“物 理化学” 课做助教)、复旦大学的吴浩青教授(物理 化学(电化学)专家、中国科学院院士, 我的博士生 导师)、中国科学院化学研究所的钱人元研究员(我 国高分子物理的奠基人之一、中国科学院院士, 我 的博士后导师)和曹锯研究员 (现在华南理工大学 工作, 高分子和有机固体专家、中国科学院院士, 我博士后研究期间的课题组长)、日本分子科学研 究所的井口洋夫教授(有机半导体的开创者和奠 基人之一、日本学士院院士、中国科学院外籍院 士, 1988.10-1991.4, 我在他的课题组访问研究两 
年半)和美国加州大学圣芭芭拉分校(UCSB)的 Alan J. Heeger 教授(导电聚合物的发现者之一、 2000 年诺贝尔化学奖获得者、美国科学院院士、 中国科学院外籍院士, 1997.6-1998.6 我在他的课 题组访问研究 1 年)。我也有许多优秀的研究生, 他们在学期间为我的研究工作增添了光彩、毕业 之后独立开展研究工作取得的成果成为了我骄傲 的资本。

我的研究生涯起步较晚, 79 年读硕士研究生 时已经 31 岁, 88 年博士后出站留化学所工作时 40 岁。不过, 我的研究经历仍比较丰富, 硕士生 阶段的研究方向为物理化学中的物质结构和化学 热力学, 研究课题是钙钛矿型催化剂 $\mathrm{LaCoO}_{3}$ 的冷 冻干燥制法。博士生阶段的研究方向是物理化学 中的电化学动力学, 研究课题是锂电池中的电化 学嵌入反应, 具体研究锂在立方晶体硫化铅电极 中的电化学嵌入反应机理和反应动力学。博士后 期间开展导电聚合物的电化学研究, 主要开展导 电聚吡咯的电化学聚合和电化学性质研究。留化 学所工作之后到 2000 年前后, 继续开展导电聚合 物电化学研究。1997 年之后研究方向逐渐转向共 轭高分子光电子材料和器件, 包括聚合物发光电 化学池和聚合物发光二极管、以及无机半导体量 子点的溶液法制备以及量子点发光二极管, 2000 年之后研究方向逐渐集中到聚合物太阳电池光伏 材料和器件, 最近还开展了钙钛矿太阳电池方面 的研究工作。我感到幸运的是, 我的研究生涯一开 始就接触到神奇的钙钛矿结构材料, 最近某些有 机-无机杂化钙钛矿和全无机钙钛矿已成为太阳 电池中的明星光伏材料。我 2000 年较早进入聚合
物太阳电池这一研究领域, 后来聚合物太阳电池 成为热门研究领域, 近年来获得快速发展。尤其值 得一提的是, 当前我国学者在引领聚合物太阳电 池研究领域的发展。但是感到遗憾的是, 我是国际 上最早开展锂电池电化学嵌入反应的研究者之 一, 然而在后来锂离子电池的研究和应用获得快 速发展的时候我却离开了这一研究领域。不过我 不后悔, 我喜欢现在开展的聚合物太阳电池光伏 材料和器件研究, 我后面的人生梦想就是实现聚 合物太阳电池的实际应用和商品化、为绿色能源 的发展做出贡献。

我培养研究生起步更晚, 1993 年 45 岁时才招 收第一位硕士研究生。现在的学者不到 45 岁已经 是大名人和桃李满天下了。不过让我感谢欣慰的 是, 我仍然有不少学生在学期间取得了具有重要 创新性研究成果, 走上工作岗位后成为了各自领 域有重要影响的学者。本专辑的论文部分反映了 他们研究成果的影响。我提倡 “快乐科研”, 不会 批评学生, 也未要求学生加班加点。但是我的学生 大部分都非常努力, 这主要是要让他们热爱自己 的研究工作, 同时得益于中科院化学所有一个努 力工作、积极向上的研究氛围。

我的座右铭是: 顺其自然、抓住机会, 致力科 研、乐在其中。我信奉 “一分为二” 的哲学观, 任 何事情都有好的一面也都有不好的一面, 因此任 何事情不必强求，应顺其自然。但这决不等于碌碌 无为、没有追求。我相信 “天道酬勤”, 习惯于努 力工作, 最怕浪费时间。我喜欢一位草根艺人为我 写的人名诗的中间两句: “永远自奋发、舫行搏风 浪”。我觉得这像是我的人生写照。 